\title{
Anastomotic Leakage Using Linear Stapling Device with Pre-attached Bioabsorbable Polyglycolic Acid Felt After Laparoscopic Anterior Resection
}

\author{
SEIICHIRO YAMAMOTO, TOSHIO KANAI, KOJI OSUMI, KIKUO YO, KIMINORI TAKANO, MAI TSUTSUI, \\ RYO NAKANISHI, YUSUKE YOSHIKAWA, YASUSHI KANEKO and MOTOHITO NAKAGAWA
}

Division of Surgery, Hiratsuka City Hospital, Hiratsuka, Japan

\begin{abstract}
Aim: Many studies have evaluated the risk factors for anastomotic leakage after laparoscopic anterior resection. In this study in order to increase the tightness of anastomoses and prevent bleeding from their staple lines, a linear stapler with pre-attached bioabsorbable polyglycolic acid (PGA) felt was used for rectal transection, and the short-term surgical outcomes were evaluated. Patients and Methods: A prospective registry of 62 patients with rectosigmoidal or rectal carcinoma who initially underwent laparoscopic anterior resection using PGA felt for rectal transection was reviewed. Results: The overall frequency of anastomotic leakage was 1.6\% (1/62), and none of the patients developed postoperative staple line bleeding or other adverse events related to the use of PGA felt. Conclusion: The frequency of anastomotic leakage was relatively low, and therefore the use of a linear stapler with pre-attached bioabsorbable PGA felt might reduce the risk of adverse events related to anastomosis, especially anastomotic leakage.
\end{abstract}

Controversy persists concerning the appropriateness of laparoscopic surgery for patients with rectal carcinoma due to uncertainty regarding its oncological outcomes compared with those of open surgery $(1,2)$. Although many studies have demonstrated that laparoscopic and open surgery for rectal carcinoma have similar short-term complications rates, the devices and techniques used for laparoscopic anterior resection (AR) differ from those used for open AR, which suggests that the risk factors for anastomotic leakage might also differ between laparoscopic AR and open AR (3-5).

Correspondence to: Dr. Seiichiro Yamamoto, Division of Surgery, Hiratsuka City Hospital, 19-1-1, Minamihara, Hiratsuka, Kanagawa, 254-0065, Japan. Tel: +81 463320015, Fax: +81 463314585, e-mail: miyamamo@jcom.home.ne.jp

Key Words: Laparoscopic anterior resection, polyglycolic acid (PGA) felt, anastomotic leakage.
Anastomotic leakage is the most important complication after AR for rectal carcinoma and occurs at frequencies ranging from 1.0 to $23 \%$ (3-8). It contributes not only to postoperative morbidity and mortality, but also to local recurrence and poor functional outcomes (9). Several studies have evaluated the risk factors for anastomotic leakage in laparoscopic AR $(10,11)$. Recently, the use of a linear stapler with pre-attached bioabsorbable polyglycolic acid (PGA) felt in distal pancreatectomy and gastrointestinal surgery was reported to be safe and effective $(12,13)$. At our Institution, in order to increase the tightness of anastomoses and prevent bleeding from their staple lines, a linear stapler with PGA felt has been used to perform rectal transection. Herein, we present the short-term surgical outcomes of these procedures.

\section{Patients and Methods}

Between December 2014 and August 2017, we performed 62 continuous laparoscopic AR using PGA felt for rectal transection in patients with rectosigmoidal or rectal carcinoma. The laparoscopic resection techniques have been thoroughly described previously, and the patient's tumors were treated by tumor-specific or total mesorectal excision (14). The details of the staplers with pre-attached PGA felt (Endo GIA ${ }^{\mathrm{TM}}$ reinforced reload with TriStaple ${ }^{\mathrm{TM}}$, purple reload, 60-mm or 45-mm long; Medtronic, Minneapolis, USA) have been described previously $(12,13)$. In the rectal transection procedures, the first cartridge was either a 60$\mathrm{mm}$ or $45-\mathrm{mm}$ purple reinforced cartridge. If two or more cartridges were required for rectal transection, a stapler with or without PGA felt was used based on the surgeon's judgement. A stapler with an automatic anastomotic device (DST Series ${ }^{\mathrm{TM}}$ EEA $^{\text {TM }}$ Stapler, Medtronic, Minneapolis, USA) was used for the anastomosis.

Decisions about whether a protective ileostomy should be performed or whether a transanal decompression tube should be used were based on the surgeon's technical evaluation of the quality of the anastomosis. Tumor locations were defined according to the General Rules for Clinical and Pathological Studies on Cancer of the Colon, Rectum and Anus published by the Japanese Society for Cancer of the Colon and Rectum (15). 
Table I. Patient characteristics.

\begin{tabular}{lc}
\hline No. of patients & 62 \\
Gender, male: female & $44: 18$ \\
Mean age (range), years & $67(34-85)$ \\
Mean body mass index (range), $\mathrm{kg} / \mathrm{m}^{2}$ & $23.6(17.1-35.2)$ \\
ASA, I:II, $\mathrm{n}$ & $26: 36$ \\
Location, $\mathrm{n}$ & \\
Rectosigmoid & 17 \\
Upper rectum & 34 \\
$\quad$ Lower rectum & 11 \\
Pathological stage, $\mathrm{n}^{*}$ & \\
I & 20 \\
II & 20 \\
III & 18 \\
IV & 4 \\
\hline
\end{tabular}

*According to the TNM Classification of Malignant Tumors (21).

The short-term surgical outcomes of laparoscopic AR using PGA felt for rectal transection in patients with rectosigmoidal or rectal carcinoma was assessed.

\section{Results}

Intraoperative photographs of rectal transection using PGA felt and the subsequent anastomosis are shown in Figure 1, and patients' demographics are summarized in Table I. All of the operations in this series were completed laparoscopically.

The operative and postoperative results are shown in Table II. There were no cases of perioperative mortality. Twelve complications occurred in 11 patients, giving a morbidity rate of $17.7 \%$ (11/62). Anastomotic leakage occurred in one patient $(1.6 \%)$. The postoperative course of the patient with anastomotic leakage was uneventful, and they were managed with conservative therapy. One patient required a reoperation because of a ureteral injury. Only one staple cartridge was used during the rectal transection in 32 patients $(51.6 \%)$.

All of the patients in which a protective ileostomy was made underwent ileostomy closure, except for the patients that were operated on within 2 months.

\section{Discussion}

This is the first study to report that laparoscopic AR performed using a linear stapler with pre-attached PGA felt produced favorable outcomes. The incidence of anastomotic leakage in laparoscopic AR (1.6\%) was lower than has been reported previously. The use of pre-attached PGA felt did not increase the frequency of adverse events. In fact, it might reduce the risk of adverse events related to anastomosis in laparoscopic AR, especially anastomotic leakage.
Table II. Intraoperative and postoperative results of laparoscopic anterior resection using a linear stapling device with pre-attached bioabsorbable polyglycolic acid felt.

\begin{tabular}{lc}
\hline Median operative time (range), min & $253(152-510)$ \\
Median blood loss (range), ml & $10(0-450)$ \\
Conversion, $\mathrm{n}$ & 0 \\
Lateral lymph node dissection, $\mathrm{n}$ & 7 \\
Temporary stoma at the first operation, $\mathrm{n}$ & 38 \\
Transanal decompression tube, $\mathrm{n}$ & 26 \\
Number of stapler cartridges & \\
fired for rectal transection, $\mathrm{n}$ & \\
1 & 32 \\
2 & 28 \\
3 & 2 \\
Median liquid intake (range), days & $1(1-2)$ \\
Median solid intake (range), days & $(1-10)$ \\
Median hospital stay (range), days & $(8-59)$ \\
Mortality, $\mathrm{n}$ & 0 \\
Morbidity, $\mathrm{n}$ & \\
Ileus & 3 \\
Wound infection & 2 \\
Chylous ascites & 2 \\
Anastomotic leakage & 1 \\
Neurogenic bladder, urinary retention & 1 \\
Peptic ulcer hemorrhage & 1 \\
Ureter injury & 1 \\
Intra-abdominal bleeding & \\
\hline
\end{tabular}

Clearly, a strict clinical study will be necessary to confirm whether the frequency of anastomotic leakage is reduced by the use of pre-attached PGA felt. However, in a previous prospective multicenter cooperative study (Lap RC) conducted in Japan, the frequency of anastomotic leakage in laparoscopicAR was found to be $8.3 \%(5,14)$. It will be necessary to accumulate a considerable number of patients to perform a superiority trial examining whether the frequency of anastomotic leakage can be reduced by using pre-attached PGA felt. Compared with those in the Lap RC study, the subjects of the present study were characterized by higher frequencies of advanced clinical and pathological stages, old age, and high body mass index values, which were also found in randomized controlled trials carried out in Europe and the US $(2,16,17)$. On the other hand, the proportion of patients in which protective stomas were indicated was high, and this should be taken into consideration. Despite these differences, the preliminary results described in this report suggest that the use of pre-attached PGA felt might reduce the frequency of anastomotic leakage.

With respect to laparoscopic AR, some reports have suggested that the risk of anastomotic leakage increases with the number of cartridges used for rectal transection $(4,18)$. On the other hand, few reports have indicated that the frequency of anastomotic leakage varies depending on the 

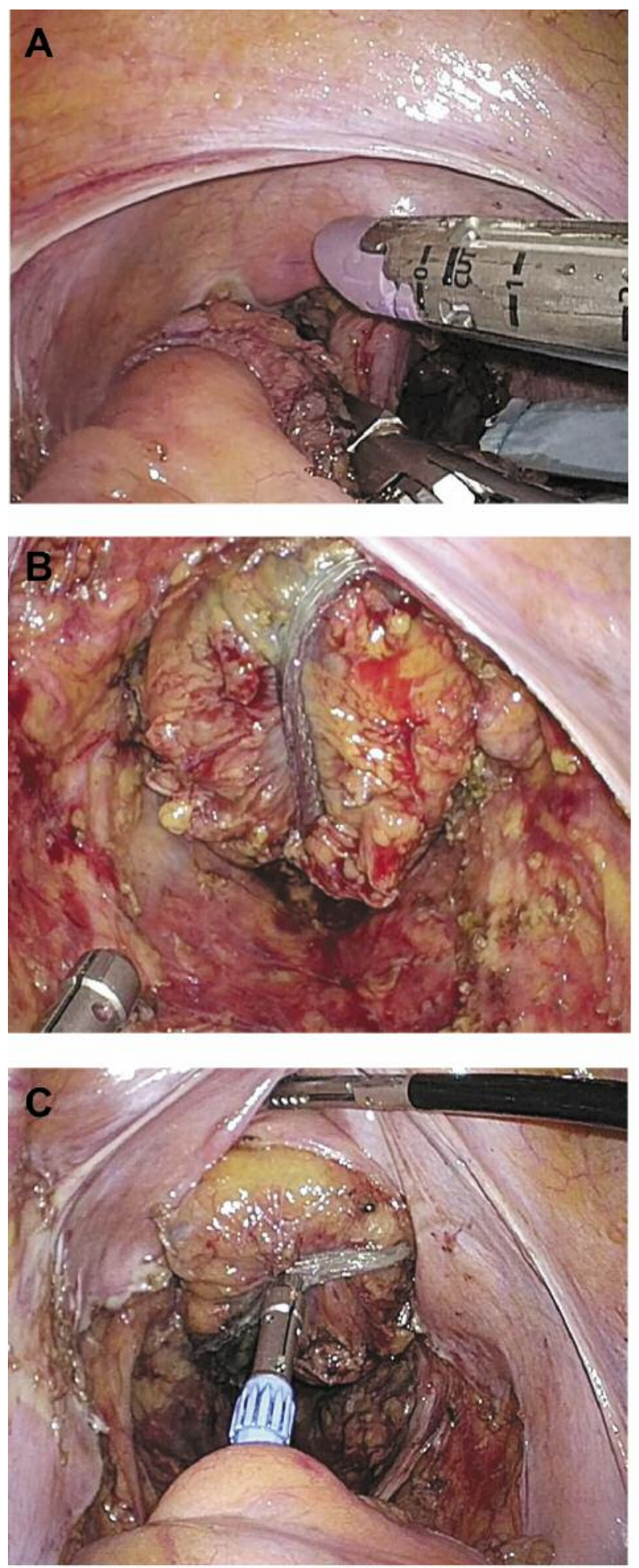

Figure 1. Intraoperative photographs of rectal transection using polyglycolic acid (PGA) felt and the subsequent anastomosis. A: After isolation of the rectum, linear stapling device with pre-attached PGA felt was introduced. B: Staple line of the linear stapling device with preattached PGA felt. C: The puncturing cone was pushed through the linear staple line. device used for rectal transection/anastomosis. It is theoretically reasonable that the frequency of anastomotic leakage would be reduced by reinforcing a staple line created by a normal laparoscopic linear stapler with PGA felt to increase its pressure resistance, but further accumulation of patients is necessary to confirm this. The concept of reinforcing a linear staple line with material as a method for preventing leaks and bleeding has been reported in sleeve gastrectomy and lung surgery $(19,20)$. However, the material is usually prepared manually. In the Endo GIA ${ }^{\mathrm{TM}}$ reinforced reload with Tri-Staple ${ }^{\mathrm{TM}}$ device (Medtronic, Minneapolis, USA), which we used in this study, the material for reinforcement is pre-attached to the linear stapler, and we did not need to prepare the device, which made it much easier to use. On the other hand, in the double stapling technique, a circular stapler is used together with a linear stapler, and the pressure resistance of the resulting staple lines might be further increased by using a similar reinforcement material with a circular stapler. The development of such a device is anticipated.

This study is limited in that it only involved a single center, and the number of patients was small. Moreover, it was not a comparative study. A strict clinical trial is necessary to confirm that anastomotic leakage can be reduced by using pre-attached PGA felt, and we consider that the safety of pre-attached PGA felt is just beginning to be evaluated.

In conclusion, the use of a linear stapler with pre-attached bioabsorbable PGA felt might reduce the risk of adverse events related to anastomosis, especially anastomotic leakage. Based on the results of this study, it would be helpful to conduct a strict clinical trial examining whether the frequency of anastomotic leakage could be reduced by using this device, although it might be difficult to perform such a trial from the perspective of case accumulation.

\section{References}

1 Stevenson AR, Solomon MJ, Lumley JW, Hewett P, Clouston AD, Gebski VJ, Davies L, Wilson K, Hague W, Simes J and ALaCaRT Investigators: Effect of laparoscopic-assisted resection $v s$. open resection on pathological outcomes in rectal cancer: The ALaCaRT Randomized Clinical Trial. JAMA 314: 1356-1363, 2015.

2 Fleshman J, Branda M, Sargent DJ, Boller AM, George V, Abbas M, Peters WR Jr, Maun D, Chang G, Herline A, Fichera A, Mutch M, Wexner S, Whiteford M, Marks J, Birnbaum E, Margolin D, Larson D, Marcello P, Posner M, Read T, Monson J, Wren SM, Pisters PW and Nelson H: Effect of laparoscopicassisted resection $v s$. open resection of stage II or III rectal cancer on pathologic outcomes: The ACOSOG Z6051 Randomized Clinical Trial. JAMA 314: 1346-1355, 2015.

3 Yamamoto S, Fujita S, Akasu T, Inada R, Moriya $\mathrm{Y}$ and Yamamoto S: Risk factors for anastomotic leakage after laparoscopic surgery for rectal cancer using a stapling technique. Surg Laparosc Endosc Percutan Tech 22: 239-243, 2012. 
4 Park JS1, Choi GS, Kim SH, Kim HR, Kim NK, Lee KY, Kang SB, Kim JY, Lee KY, Kim BC, Bae BN, Son GM, Lee SI and Kang $\mathrm{H}$ : Multicenter analysis of risk factors for anastomotic leakage after laparoscopic rectal cancer excision: the Korean laparoscopic colorectal surgery study group. Ann Surg 257: 665671,2013

5 Tanaka K, Okuda J, Yamamoto S, Ito M, Sakamoto K, Kokuba $\mathrm{Y}$, Yoshimura $\mathrm{K}$ and Watanabe M: Risk factors for anastomotic leakage after laparoscopic surgery with the double stapling technique for stage 0/I rectal carcinoma: a subgroup analysis of a multicenter, single-arm phase II trial. Surg Today 47: 12151222, 2017.

6 Bennis M, Parc Y, Lefevre JH, Chafai N, Attal E and Tiret E: Morbidity risk factors after low anterior resection with total mesorectal excision and coloanal anastomosis: a retrospective series of 483 patients. Ann Surg 255: 504-510, 2012.

7 Katsuno H, Shiomi A, Ito M, Koide Y, Maeda K, Yatsuoka T, Hase K, Komori K, Minami K, Sakamoto K, Saida Y and Saito $\mathrm{N}$ : Comparison of symptomatic anastomotic leakage following laparoscopic and open low anterior resection for rectal cancer: a propensity score matching analysis of 1014 consecutive patients. Surg Endosc 30: 2848-2856, 2016.

8 Kim CW, Baek SJ, Hur H, Min BS, Baik SH and Kim NK: Anastomotic leakage after low anterior resection for rectal cancer is different between minimally invasive surgery and open surgery. Ann Surg 263: 130-137, 2016.

9 Mirnezami A1, Mirnezami R, Chandrakumaran K, Sasapu K, Sagar P and Finan P: Increased local recurrence and reduced survival from colorectal cancer following anastomotic leak: systematic review and meta-analysis. Ann Surg 253: 890-899, 2012.

10 Kawada K, Hasegawa S, Hida K, Hirai K, Okoshi K, Nomura A, Kawamura J, Nagayama S and Sakai Y: Risk factors for anastomotic leakage after laparoscopic low anterior resection with DST anastomosis. Surg Endosc 28: 2988-2995, 2014.

$11 \mathrm{Qu} \mathrm{H}$, Liu Y and Bi DS: Clinical risk factors for anastomotic leakage after laparoscopic anterior resection for rectal cancer: a systematic review and meta-analysis. Surg Endosc 29: 36083617, 2015.

12 Yamashita YI, Tsujita E, Chikamoto A, Imai K, Kaida T, Yamao T, Umezaki N, Nakagawa S, Hashimoto D and Baba H: Linear stapling device with pre-attached bioabsorbable polyglycolic acid felt reduces postoperative pancreatic fistula after distal pancreatectomy. Anticancer Res 37: 1865-1868, 2017.

13 Naito M, Sato T, Nakamura T, Yamanashi T, Miura H, Tsutsui A and Watanabe M: Secure overlap stapling using a linear stapler with bioabsorbable polyglycolic acid felt. Asian J Endosc Surg 10: 308-312, 2017.
14 Yamamoto S, Ito M, Okuda, Fujii S, Yamaguchi S, Yoshimura K, Sugihara K and Watanabe M, for the Japan Society of Laparoscopic Colorectal Surgery: Laparoscopic surgery for stage 0/I rectal carcinoma: short-term outcomes of a single-arm phase II trial. Ann Surg 258: 283-288, 2013.

15 Japanese Society for Cancer of the Colon and Rectum: General Rules for Clinical and Pathological Studies on Cancer of the Colon, Rectum and Anus (in Japanese), 8th edn. Tokyo, Japan: Kanehira-Syuppan; 2013.

16 Guillou PJ, Quirke P, Thorpe H, Walker J, Jayne DG, Smith AM, Heath RM, Brown JM and MRC CLASICC trial group: Shortterm endpoints of conventional versus laparoscopic-assisted surgery in patients with colorectal cancer (MRC CLASICC trial): multicentre, randomised controlled trial. Lancet 365 : 1718-1726, 2005.

17 van der Pas MH, Haglind E, Cuesta MA, Fürst A, Lacy AM, Hop WC, Bonjer HJ and Colorectal Cancer Laparoscopic or Open Resection II (COLOR II) Study Group: Laparoscopic versus open surgery for rectal cancer (COLOR II): short-term outcomes of a randomised, phase 3 trial. Lancet Oncol 14: 210218, 2013.

18 Ito M, Sugito M, Kobayashi A, Nishizawa Y, Tsunoda Y and Saito N: Relationship between multiple numbers of stapler firings during rectal division and anastomotic leakage after laparoscopic rectal resection. Int J Colorectal Dis 23: 703-707, 2008.

19 Choi YY, Bae J, Hur KY, Choi D and Kim YJ: Reinforcing the staple line during laparoscopic sleeve gastrectomy: Does it have advantages? A meta-analysis. Obes Surg 22: 1206-1213, 2012.

20 Hirai K, Kawashima T, Takeuchi S and Usuda J: Covering the staple line with a polyglycolic acid sheet after bullectomy for primary spontaneous pneumothorax prevents postoperative recurrent pneumothorax. J Thorac Dis 7: 1978-1985, 2015.

21 Sobin LH, Gospodarowicz MK and Wittekind C: TNM Classification of Malignant Tumors, Seventh Edition. Chichester, UK: Wiley-Blackwell; 2011. 